\title{
ACADEMIC DISHONESTY AMONG INTERNATIONAL STUDENTS IN HIGHER EDUCATION
}

\author{
Krishna K. Bista, Arkansas State University
}

University instructors address and want to eschew student academic misconduct. These educators presume that students understand fully what cheating and plagiarism are. However, the issue of academic dishonesty among international students is complex and difficult. This study investigated the perceptions of international undergraduate and graduate students in a southern U.S. university about possible causes for academic misbehavior. Results reveal several causal variables: previous learning style, English language proficiency, unfamiliarity with American academic cultures, relationship between student and teacher, and availability of technical and educational resources associated with academic dishonesty.

Academic misconduct in higher learning institutions remains prevalent among students at both the undergraduate and graduate levels (Lipson $\&$ McGavern, 1993; Love, 1997). Academic misconduct is more prevalent among international students than students educated in English-speaking countries (Arkoudis, 2007; Park, 2003). As is typical of many institutions, the University of Alberta (2010) defines academic dishonesty as cheating (using unauthorized notes or study aids on an examination), plagiarism (using others' work as their own without acknowledging the contribution of the author), fabrication (falsifying any information or

Thanks to Charlotte Foster and David Cox at the Center for Excellence, Arkansas State University, and Barry S. Davidson and Andrew Creamer at the College of Education at Troy University. 
data, unauthorized access, misuse of a vailability of computer system or alteration of computerized records), deception (providing false information to the instructor), and sabotage (preventing others from completing their course work).

\section{Variables Affecting Plagiarism}

Some researchers have suggested that academic honesty offenses may result from misunderstanding of course policy or definitions of misbehavior such as plagiarism rather than a deliberate intention to cheat (Bamford \& Sergiou, 2005; Evans \& Youmans, 2000). Broadly speaking, scholars have categorized plagiarism into two groups: intentional and unintentional (Bamford \& Sergiou, 2005; Hammond, 2002; Larkham \& Manns, 2002; Park, 2003). Hall (2004) found several reasons for plagiarism, such as differing cultural values, personality factors, stress, peer pressure, and contextual factors. Studies conducted in China, Latvia, Lithuania, and the United States revealed historical, political, economic, and technical influences as major variables of plagiarism (Russikoff, Fucaloro, \& Salkauskiene, 2003). A study at the University of Alberta (2010) mentioned poor time management and organizational skills, strong home culture, pressure for scholarship and jobs, and misunderstanding of course rules and regulations leading individuals to acts of plagiarism. McCabe, Trevino, and Butterfield (2001) suggest contextual factors such as peer behavior as the most powerful influence to educational cheating.

\section{Previous Learning Style and Culture}

In many cultures, the ability of learners to integrate the words of others in harmony with one's own was considered an academic practice (Cammish, 1997). Fleck (2000) investigated the concept of cheating in urban and rural Nepal from an ethnocentric perspective. He found that the underlying causes of cheating were grounded in Nepal's hierarchical cultural values: education is considered a status or rank rather than a process of learning, and cheat sheets, whispers, and copied answers were examination reality in many of Nepal's public schools. Such academic practices occur in many ethnic-oriented tribal communities, as Ballard and Clanchy (1991, cited in Hall, 2004, p. 4) explained: "In a Confucian, Buddhist, Hindu or Islamic society, for example, the ability to quote from 
sacred writings, from the saying of the ages, from the words of leading scholars, is the essence of scholarship."

Nazir and Aslam (2010) studied perceptions of academic dishonesty among Pakistani undergraduate and graduate students in different universities and found that more than half of the students studied were involved in dishonest acts such as helping other students copy homework assignments, exam papers, or graded project reports. These students believed that cheating and copying were not serious offenses and that there was no penalty for such behaviors.

In the Western world, knowledge acquisition is an intellectual exercise whereby one applies and manipulates information and data from various sources (Hellsten \& Prescott, 2004). However, in non-Western cultures, rote learning and memorization are still widely practiced, and the degree of plagiarism is higher in graduate students than in undergraduate students due to the greater demand for critical and analytical writing (Scheyvens, Wild, \& Overton, 2003). Some scholars have focused on the fact that many international students have already fossilized their learning attitudes into culturally influenced beliefs and behaviors from years of schooling at their home university, and it appears they may be unable to alter those behaviors in the American classroom (Carroll, 2002; Ryan, 2000).

Academic attribution and the use of others' published material is greatly influenced by culture. Russikoff et al. (2003) found common economic practices in communist and post-Soviet settings to be influential in plagiarism. These researchers found students copying from each other and comparing composition lengths on a free-writing assignment in a Latvian institution of higher learning. When questioned by the researchers, students responded, "We do it this way! We always do it this way! We copy and our teachers all know we just do it!" (p. 110). Chinese students state that plagiarism and copying is "a pedagogical practice" (Russikoff et al., 2003, p. 112). Fleck (2000), studying the nature of cheating in Nepal's public schools, found that students preferred copying answers from each other in free-writing assignments.

\section{Communication Difficulties}

The lack of English language proficiency and awareness of standard English citation conventions may contribute to plagiarism and cheating (Hyland, 2001; Park, 2003). Language barriers (Biggs \& Burville, 2003) and difficulties in separating one's own thoughts from information gathered from texts and properly acknowledging the sources can also 
lead to plagiarism (Hall, 2004). In addition, international students may not have adequately developed such skills as essay writing, note taking, group work, and presentation, leading them to take academic shortcuts on academic tasks. Robertson, Line, Jones, and Thomas (2000) mentioned difficulties in comprehending the content of lectures, difficulties in understanding subject-specific terminology, high speed of delivery in lectures and seminars, and difficulties in interpreting the English language as reasons that international students plagiarize.

\section{Lack of Familiarity with the Culture of Academics}

The cultural difference of what constitutes public knowledge versus private knowledge is a central phenomenon of academic misconduct in some Asian and European educational settings. Some cultural groups do not regard plagiarism as a serious violation (Cammish, 1997). The University of Alberta (2010) suggested that 60 percent of international students interviewed stated they could not distinguish between paraphrased and plagiarized text. Carroll (2002) and Ryan (2000) highlighted the problems of such students who did not fully understand the differences among quoting, embedding sources, and plagiarism. In some cultural contexts, cheating is considered a learned behavior (DiPietro, 2010). For example, Italian students viewed copying from other sources as acceptable and as a mark of respect to the original author (cited in Hyland, 2001). Hammond (2002, cited in Hall, 2004, p. 1) listed the following reasons international students gave for plagiarizing:

\footnotetext{
"I couldn't keep up with the work."

"The lecturer/tutor doesn't care, so why should I?"

"I have to succeed. Everyone expects me to succeed, and I expect it, too."

"I don't understand what I'm expected to do to avoid plagiarism."

"I can't do this! I will have to copy."

"But you said, 'Work together."”

"But paraphrasing would be disrespectful."

"I got desperate at the last moment."
}

Both international and domestic students indicate that normal academic pressures can lead to academic misconduct. Russikoff et al. (2003) found basic reasons that some individuals plagiarize: "It takes less time to complete an assignment, the ideas and writing are better, it is easier than having to produce original work, and teachers do not care" (p. 113). 


\section{Student-Teacher Relationship}

Student-teacher relationships play a crucial role in determining the degree of academic dishonesty for international students. Teachers are highly respected authority figures in Bhutan, China, India, Japan, Nepal, and other Asian countries. Students in such cultures often consider teachers' opinions or information from books as the ultimate truth without question, and they reproduce this type of information verbatim (Ninnes, Aitchison, \& Kalos, 1999; Robertson et al., 2000). Ryan (2000) points out that students from some cultures believe it is impolite to quote a reference or information from other sources because "this indicates that the teacher does not know that the text exists" (p. 23). Hall (2004) suggests that in any collectivist culture, the teacher determines the types of information that his or her students require to become successful. Knowledge in such cultures is considered "communal property" that anyone can use without acknowledgment (Carroll, 2002; Ryan, 2000).

Little research has been conducted on how undergraduate and graduate students are socialized in behaviors and attitudes related to academic misconduct. In a 1984 study at the undergraduate level, Nuss found that 53 percent of faculty surveyed indicated they rarely or never discussed university policies related to cheating and plagiarism with their students. A study by Love (1997) with six international graduate students found that they did not have any orientation experiences focused on the American writing culture.

\section{Access to Educational Resources}

Having access to the electronic and print versions of educational materials is essential for both educators and learners to maximize learning. However, many learners in technologically underdeveloped countries lack easy access to these resources. Limited teaching resources such as lecture notes and textbooks place burdens on instructors and students alike in China, India, and Nepal (Biggs, 1996; Fleck, 2000; Ninnes et al., 1999). In addition, poor quality of teaching aids, ineffective class management, inappropriate assessment, lack of expertise in education, and an authoritarian approach have all been associated with academic misbehavior (Fleck, 2000; Hellsten \& Prescott, 2004).

It is often argued that students in American and other Western universities are highly involved in academic misconduct because they have easy access to Internet resources (Russikoff et al., 2003). However, students and instructors in poor Asian countries without easy access to the Internet or library resources are also prone to cheating and plagiarism. 


\section{Psychological Pressure and Adjustment Issues}

Psychological pressures that international students face in the process of transitioning to study in the United States are associated with academic performance and misconduct. After arrival in a new country, international students face a number of challenges in adjusting to living and learning, including culture shock and financial problems, which may have an impact on their study plans, academic motivation, and attention to assignments and course work. These adjustment problems can vary by country of origin, race, ethnicity, English language proficiency, and collective versus individualist cultural orientation (Constantine, Anderson, Berkel, Caldwell, \& Utsey, 2005; Poyrazli \& Grahame, 2007).

The American university can also contribute to adjustment difficulties and the pressure to cheat when its international student services fall short by not making social connections to international students' home cultures, language, food, and social life. As a result, international students may experience negative psychological responses such as tension, confusion, depression, homesickness, disorientation, feelings of isolation, alienation, and powerlessness (Poyrazli \& Grahame, 2007), often leading to lower academic achievement (Poyrazli \& Grahame, 2007; Rai, 2002; Ying, 2002). Eisenberg, Golberstein, and Gollust (2007) indicate that 37 to 84 percent of international students did not receive free counseling, mental health services, or psychotherapy. When international students experience psychological, social, and academic pressures, they may be at greater risk of not following the standards and guidelines of American academic honesty requirements.

Much has been written about academic dishonesty and plagiarism among college students, but little has been done to study the causes of plagiarism among international students. As we have seen, international students with different culture, language, and learning environment backgrounds face several academic and nonacademic problems. I conducted a study of international students to answer the following questions:

- What are the major adjustment challenges for international students who are seeking academic degrees in the United States?

- Do social, cultural, and economic issues and psychological stress make international students prone to increased rates of plagiarism?

- Do home country teaching and learning styles contribute to documentation and citation difficulties?

- How do international students perceive cheating and plagiarism? 


\section{Methodology}

I gathered data from international students studying at a southern university in 2010 using a questionnaire distributed by e-mail and in person. The questionnaire surveyed demographic factors such as gender, nationality, educational degree, and issues related to academic dishonesty. The focus of the study was to better comprehend the social, cultural, and psychological backgrounds of international students. Of the 300 international students invited to respond, 230 participated in the questionnaire, distributed by country of origin as follows: Australia (4), Azerbaijan (1), Belarus (1), China (66), Japan (10), India (30), Kenya (10), Malaysia (5), Morocco (4), Nepal (36), New Zealand (2), Norway (2), Poland (5), the Netherlands (4), Togo (2), Turkey (2), Saudi Arabia (23), South Korea (16), and Sweden (3). Four participants did not mention their country of origin. Female participants ( 51.6 percent) slightly outnumbered male participants (48.4 percent). Academically, 58.3 percent of the students were undergraduates, 33.3 percent were graduate students, and 8.3 percent were in English as a Second Language programs.

\section{Findings}

The data obtained from the study were analyzed from the perspective of student learning styles and cultures. The findings of this study fall into six main categories.

\section{Previous Learning Style and Culture}

Some international students have learning styles that may be different from those observed in traditional American classrooms. In many emerging Asian countries, teachers and educators follow traditional modes of instruction in the class. In a response to a question regarding previous learning and exam preparation in their home country, 93.3 percent of international students admitted that they primarily memorized information, 43.3 percent acknowledged use of group study, 50 percent were encouraged to prepare by rote learning, and 10 percent experienced collaborative testing and sharing answers for exams.

In response to a question on writing and information-finding conventions, 76.7 percent of respondents admitted that they did not follow the American Psychological Association or Modern Library Association writing format on class assignments in their previous work at their home university. This indicates that the majority of survey participants followed 
standard writing formats only in American schools. Similarly, 16.7 percent agreed that it was acceptable to consult with a friend when writing or studying, 26.7 percent believed that finding answers from online sources was acceptable, and 30 percent shared that getting help from others in taking an online exam or completing a take-home test was appropriate.

\section{Incompetence and Other issues}

This study indicated that English was a major language barrier for foreign students. More than half ( 58 percent) of the participants were undergraduate students, and their level of English proficiency was rated as just "satisfactory." Of the remaining participants, 10 percent rated themselves as a limited user, 11 percent as a moderate user, 12 percent as a good user, and 8 percent as a very good user.

When students are not interested in their programs of study, they are likely to slack off on their academic course work. For example, when asked what academic problems they faced in their course work, 27.5 percent of respondents supported the statement, "I didn't have a high enough score on the TOEFL/IELTS [Test of English as a Foreign Language/ International English Language Testing System] and I had to do ESL [English as a Second Language] program"; 10 percent selected, "I did a prerequisite or foundation course as I changed my major"; 2.5 percent chose, "I dropped the course because I wasn't interested"; and 37.5 percent responded, "I am just doing this program because I didn't have any other choice." In addition, 45 percent responded, "I found my own English not good enough." These responses suggest that many international students were pursuing university study without a particular interest in the academic field. Students may not progress well academically when they do not enter the program or take courses of their choice. The method of classroom instruction in secondary schools and universities in their home country plays a vital role in determining English competency for many international students. The survey showed that 69 percent of students were taught in a non-English local dialect or native language. In addition, 50 percent interacted with their professors in the local language while they were in their home country. These factors indicate that international students may not be acquiring strong language competence in English in their home countries. For most international students, face-to-face encounters with native English speakers did not occur until their entry into the United States. As a result, many students cannot express themselves comfortably, have low self-esteem, and fear making mistakes when they approach their professors in an American classroom setting (Cammish, 1997). 


\section{Being Unfamiliar with the Culture of Academics}

In response to the question, "Why do you think that many students copy materials from the Internet and textbooks while doing reports, course assignments, or theses?" more than half of the students ( 56.7 percent) indicated that they lacked knowledge of what plagiarism is. Nearly half (46.7 percent) indicated that they were unfamiliar with the academic culture of American schools. Forty percent admitted cheating on exams or course assignments because of the pressures of timed exams. Furthermore, 10 percent cheated on the tests and admitted taking advantage of the instructor's permissive leniency. The results of this study support the findings of previous research that international students do not know what plagiarism truly means (Cammish, 1997; DiPietro, 2010; Hall, 2004; University of Alberta, 2010).

\section{Student-Teacher Relationship}

Cultural values that international students hold determine the form and style of communication, interpersonal behavior, and interaction between students and teachers. In the collective culture of Asian countries, learners may have a unique classroom demeanor-very polite, respectful, and obedient. Many foreign students find American classroom cultures disorienting when they have to navigate unfamiliar customs such as casual dress, students eating in class, direct communication, and calling professors by their first names.

This conflict of classroom culture is supported by student responses to the question about student-teacher interaction. Students indicated that their home country behavior practices still influenced their U.S. classroom interactions. Seventy percent responded, "I listen more and speak less"; 40 percent said, "To be silent is a part of a good discipline in the class"; and 13.3 percent responded, "There were no questions and interaction in the class," and, "I never made eye-to-eye contact while speaking." This indicates that international students in this study bear similar cultural features to those in previous studies.

\section{Access to Educational Resources}

International students, especially from developing countries such as Bhutan, China, India, Nepal, and Pakistan, may not have had access to a computer or research library in their previous academic experiences (Neuman, Khan, \& Dondolo, 2008; Rennie \& Mason, 2007). In response to the question, "How often did you use a library, computer or references while preparing term papers and class assignments in your previous study at your home university?" 26 percent reported "always," more than 
half ( 53 percent) answered "seldom," and 20 percent replied "rarely." In response to another question about their previous learning experiences in their home countries, 53 percent reported that their teachers asked them to memorize, read, and take comprehensive tests. Twenty percent of respondents said that their teachers read directly from the text with little or no explanation of content materials, whereas nearly half ( 49 percent) of the respondents stated that teachers at their previous schools did not use computers, did not conduct research, and did not assign project work. This lack of exposure to educational resources suggests that some international students are at greater possible risk for academic misinterpretation of established college norms in American institutions of higher learning.

\section{Psychological Pressure and Adjustment Issues}

Many international students experience anxiety, homesickness, and cultural and social isolation, which occur not only in the immediate transitional adjustment phase but also for many months that follow. Many students from developing countries also face financial challenges paying for academic and living expenses. Although it is illegal for international students to work off campus, some feel compelled to engage in any kind of work to support their unmet needs.

Students have a difficult time excelling in their studies and paying attention to school work if they are not socially, mentally, and economically ready. In this study, 57 percent of new international students indicated that they feared making mistakes, and 50 percent reported they did not express themselves most of the time. Nearly half ( 47 percent) of respondents shared that they felt awkward and found it difficult to speak with others, and another 37 percent suggested that anxiety impeded their ability to articulate their thoughts exactly and correctly.

Almost one in four students ( 23 percent) expected their friends could share course work with them.

When a professor asks a question in class, international students sometimes take longer to collect their thoughts or formulate an answer. Beginning instructors may not be aware that some foreign students are mentally translating words before speaking. When possible, international students like to use "beautiful sentences" from books or other resources to include in their writing to compensate for these language difficulties.

\section{Implications}

The findings from this study and previous research highlight the fact that academic misconduct is a complicated issue for international students. 
Many students do not know what plagiarism is, and their cultural and social beliefs cloud the issues of improperly borrowed sources. The goal of the instructor is to have a positive impact on learning, as well as improve communication with their students (Evans \& Youmans, 2000), and it is essential that educators teaching international students understand the social, cultural, and pedagogical background of their students and how they may or may not be aligned with U.S. academic values and behaviors (Grey, 2002). Instructors need to explain how to avoid improper documentation in college writing, and providing positive reinforcement with corrective action, instead of punishment, should become the norm. One possible solution is to offer an integrated bridge course on academic writing techniques and pitfalls for international students. Felix and Lawson (1994) and Bamford and Sergiou (2005) recommend conducting cultural reorientation programs focused on proper reference citation for international students. Ryan $(2000$, p. 56) makes these suggestions for reducing plagiarism among international students:

- Discuss what plagiarism is, and give examples.

- Explain the difference between paraphrasing and plagiarism.

- Demonstrate to students how to paraphrase, synthesize, and weave other sources into their own work.

- Show students how they are supposed to meet referencing requirement and why the requirements exist.

- State what is not permitted, describing what it is and why it is unacceptable.

- Explicitly state the consequences of not complying with the rules against plagiarism.

Changing improper writing habits of foreign students in regard to proper citation and plagiarism is hard work. Classroom educators must provide clear and explicit instructions to students about what is acceptable and what is not in writing in an academic setting. Arkoudis (2007) recommends that all teachers of students who are not native English speakers use a variety of educational approaches to avoid plagiarism.

\section{Conclusion}

The results of this study indicate that academic misconduct and plagiarism are prevalent among international students. According to the literature review and survey responses, external social, economic, and psychological pressures are the main causes of plagiarism. Many international students do not know what plagiarism is due to complex cultural 
differences as well as the learning and teaching styles of their home country. It is difficult to break the routine habits of international students (Bamford \& Sergious, 2005), and they must receive direct, explicit instruction concerning plagiarism in the preparation of research papers as well as course work. It is important for faculty to understand the divergent linguistic and cultural backgrounds of their international students. Special attention should be given to students suffering from social and psychological discomforts such as anxiety, homesickness, or cultural disorientation in the cross-cultural adjustment process. The notion of academic dishonesty must be addressed from a perspective that recognizes that international students, especially those from developing countries, come from distinct cultural, economic, and educational backgrounds.

\section{REFERENCES}

Arkoudis, S. (2007). Teaching international students: Strategies to enhance learning. Melbourne, Australia: Center for the Study of Higher Education, University of Melbourne.

Ballard, B., \& Clanchy, C. (1991). Teaching students from overseas. Melbourne, Australia: Longman Cheshire.

Bamford, J., \& Sergiou, K. (2005). International students and plagiarism: An analysis of the reasons for plagiarism among international foundation students. Investigations in University Teaching and Learning, 2(2), $17-22$.

Biggs, J. (1996). Western misconceptions of the Confucian-heritage learning culture. In D. Watkins \& J. Biggs (Eds.), The Chinese learner: Cultural, psychological, and contextual influences (pp. 45-67). Hong Kong, China: University of Hong Kong.

Biggs, J., \& Burville, J. (2003). Teaching for quality learning at university: What the student does (2nd ed.). Buckingham, England: Society for Research into Higher Education \& Open University Press.

Cammish, N. K. (1997). Studying at advanced level through English. In D. McNamara \& R. Harris (Eds.), Overseas students in higher education: Issues in teaching and learning (pp. 143-155). London, England: Routledge. Carroll, J. (2002). A handbook for deterring plagiarism in higher education.

New York, NY: Oxford University Press.

Constantine, M. G., Anderson, G. M., Berkel, L. A., Caldwell, L. D., \& Utsey, S. O. (2005). Examining the cultural adjustment experiences of African international college students: A qualitative analysis. Journal of Counseling Psychology, 52(1), 57-66. doi:10.1037/0022-0167.52.1.57 
DiPietro, M. (2010). Theoretical frameworks for academic dishonesty: A comparative review. In L. B. Nilson \& J. E. Miller (Eds.), To improve the academy: Vol. 28. Resources for faculty, instructional, and organizational development (pp. 250-262). San Francisco, CA: Jossey-Bass.

Eisenberg, D., Golberstein, E., \& Gollust, S. E. (2007). Help-seeking and access to mental health care in a university student population. Medical Care, 45(7), 594-601.

Evans, F. B., \& Youmans, M. (2000). ESL writers discuss plagiarism: The social construction of ideologies. Journal of Education, 182(3), 49-65.

Felix, U., \& Lawson, M. (1994). Evaluation of an integrated bridging course on academic writing for overseas postgraduate students. Higher Education Research and Development, 13(1), 59-69. doi:10.1080/0729436940130106

Fleck, C. (2000). Understanding cheating in Nepal. Electronic Magazine of Multicultural Education, 2(1). Retrieved from www.eastern.edu/ publications/emme/2000spring/fleck.html?

Grey, M. (2002). Drawing with a difference: Challenges faced by international students in an undergraduate business college. Teaching in Higher Education, 7(2), 153-166. doi:10.1080/13562510220124268

Hall, B. (2004). International students and plagiarism: A review of the literature. Retrieved from www.bournemouth.ac.uk/cap/documents/Plagiarism percent 20 and $\% 20$ International $\% 20$ Students.pdf

Hammond, M. (2002). Cyber-plagiarism: Are FE students getting away with words? Retrieved from www.leeds.ac.uk/educol/documents/00002055.htm Hellsten, M., \& Prescott, A. (2004). Learning at university: The international student experience. International Educational Journal, 5(3), 344-351.

Hyland, F. (2001). Dealing with plagiarism when giving feedback. ELT Journal, 55(4), 375-381. doi:10.1093/elt/55.4.375

Larkham, P., \& Manns, S. (2002). Plagiarism and its treatment in higher education. Journal of Further and Higher Education, 26(4), 339-349.

Lipson, A., \& McGavern, N. (1993, May). Undergraduate academic dishonesty at MIT: Results of a study of attitudes and behavior of undergraduates, faculty and graduate teaching assistants. Paper presented at the 33rd annual forum of the Association for Institutional Research, Chicago, IL.

Love, P. G. (1997, November). The meaning and mediated nature of cheating and plagiarism among graduate students in a college of education. Paper presented at the 22nd annual meeting of the Association for the Study of Higher Education, Albuquerque, NM.

McCabe, D. L., Trevino, L. K., \& Butterfield, K. D. (2001). Cheating in academic institutions: A decade of research. Ethics and Behavior, 11(3), 219-232. 
Nazir, M. S., \& Aslam, M. S. (2010). Academic dishonesty and perceptions of Pakistani students. International Journal of Educational Management, 24(7), 655-668. doi:10.1108/09513541011080020

Neuman, S. B., Khan, N., \& Dondolo, T. (2008). When I give, I own: Building literacy through READ community libraries in Nepal. Reading Teacher, 61(7), 513-522. doi:10.1598/RT.61.7.1

Ninnes, P., Aitchison, C., \& Kalos, S. (1999). Challenges to stereotypes of international students' prior educational experience: Undergraduate education in India. Higher Education Research and Development, 18(3), 323-342. doi:10.1080/0729436990180304

Nuss, E. M. (1984). Academic integrity: Comparing faculty and student attitudes. Improving College and University Teaching, 32(3), 140-144.

Park, C. (2003). In other words: Plagiarism by university students-Literature and lessons. Assessment and Evaluation in Higher Education, 28(5), 471-489.

Poyrazli, S., \& Grahame, K. M. (2007). Barriers to adjustment: Needs of international students within a semi-urban campus community. Journal of Instructional Psychology, 34(1), 28-45.

Rai, G. (2002). Meeting the educational needs of international students. A perspective from US schools. International Social Work, 45(1), 21-33.

Rennie, F., \& Mason, R. (2007). The development of distributed learning techniques in Bhutan and Nepal. Retrieved from ERIC Database. (ED496159)

Robertson, M., Line, M., Jones, S., \& Thomas, S. (2000). International students, learning environments and perceptions: A case study using the Delphi technique. Higher Education Research and Development, 19(1), 89-102. doi:10.1080/07294360050020499

Russikoff, K., Fucaloro, L., \& Salkauskiene, D. (2003). Plagiarism as a crosscultural phenomenon. CAL Poly Pomona Journal of Interdisciplinary Studies, 16, 109-120.

Ryan, J. (2000). A guide to teaching international students. New York, NY: Oxford Center for Staff and Learning Development.

Scheyvens, R., Wild, K., \& Overton, J. (2003). International students pursuing postgraduate study in geography: Impediments to their learning experiences. Journal of Geography in Higher Education, 27(3), 309-323. doi:10.1080/0309826032000145070

University of Alberta. (2010). Why students plagiarize: Guide to plagiarism and cyber-plagiarism. Retrieved from www.library.ualberta.ca/guides/ plagiarism/why/index.cfm

Ying, Y.-W. (2002). Formation of cross-cultural relationships of Taiwanese international students in the United States. Joumal of Community Psychology, 30(1), 45-55. doi:10.1002/jcop.1049 